\title{
The Role of Pedagogical, Environmental and Socio Economic Factors in Pupils' Retention Rate in Public Primary Schools in Lusaka, Zambia
}

\author{
Chrine, C. Hapompwe ${ }^{1}$; Martha Mbewe ${ }^{2}$; Jacqueline Siwale ${ }^{3}$ \& Caroline Nkatha Waithaka ${ }^{4}$ \\ Lecturer; Cavendish University Zambia, Faculty of Arts, Education \& Social Sciences ${ }^{1}$ \\ Graduand; Cavendish University Zambia, Bachelor of Development Studies ${ }^{2}$ \\ Lecturer; Cavendish University Zambia, Faculty of Business and Information Technology ${ }^{3}$ \\ Lecturer; Cavendish University Zambia, Faculty of Arts, Education \& Social Sciences ${ }^{4}$ \\ DOI: $10.29322 /$ IJSRP.10.08.2020.p104111 \\ http://dx.doi.org/10.29322/IJSRP.10.08.2020.p104111
}

\begin{abstract}
This was an empirical study purposed to analyse the role of pedagogical, environmental and socio economic factors in public primary schools' pupil retention in Lusaka, Zambia against the resounding concern about the reduction in number of pupils who were able to transition to upper levels after enrolment. The objectives of the study were: to describe pedagogical processes which lead to low retention rate among public primary school pupils; to explore school environmental factors which contribute to low retention rate among public primary school pupils; and to analyse socio-economic factors responsible for low retention rates among public primary school pupils. A survey method was employed incorporating a descriptive paradigm. The questionnaires were distributed to 10 selected public primary schools in Lusaka based on the District Education Board's 66 currently established public primary schools list as at 2020. The study targeted a total of 100 respondents out of which 92

$\mathrm{G}$
\end{abstract} responded successfully. The respondents comprised head teachers, deputies, school counsellors, senior teachers, class teachers, and school administrators. Questionnaire responses were subjected to analysis using excel and SPSS to gain in-depth understanding of the phenomena with the results being presented in charts, figures, tables and graphs while content responses were presented in text format. The key findings were that pedagogical factors including poor teaching approaches, methods / techniques, teacher qualifications, teacher unpreparedness and teacher attitude played a critical role in contributing to low retention of pupils in public primary schools. Environmentally, it was established that factors such as lack of adequate facilities / resources in schools e.g. text books, proper water and sanitary facilities, teacher availability, class room, furniture, school outlook and surroundings contributed to the problem. On socio economic fronts; family poverty, nutrition, child labour, loss of parent/guardian were topping the list as being prohibitive to children's perseverance and persistence in their education radar. Some Parents/guardians were said not to be able to buy school shoes, uniform and pay other minor user fees like sports or PTA fund etc, which led to some School Administrators / Head teachers sending away such children despite government policy not to chase any child on such grounds. Compounding the situation was the fact that government's policy interventions such as introduction of feeding programmes, sponsorship of orphans and vulnerable children have been negatively affected by the declining education financing levels from central government since 2016. The resultant effect overall is an increase in the number of children out of school from over 195,000 in 2015 to over 800,000 in 2019 as national aggregates. The study, therefore, recommends that educationists and policy makers need to consider the issues raised herein with great precaution and urgency so that the resources invested in the education sector will be realised with a dividend.

Index Terms- Role, Pedagogic, Environmental, Socio Economic, Retention Rate, Primary School Pupils.

\section{INTRODUCTION} lobally, governments are responsible for the education of their citizens as well as the achievement of the intended purpose of education as bases for peace, socio economic development, harmony etc. (UNESCO, 2018). This is because education is considered to be a panacea to socio economic upheavals, among others. Zambia's Education System consists of early childhood education (ECE), primary, secondary and professional or tertiary levels. The primary level, which is the concern in this discourse runs from grades 1 to 7 . For the majority this is the basic form of education that is attained and paves a way for future achievements in the academic life of the young children. In addition to the formal system, there is a non-formal education system that operates to serve, among others, displaced persons, school-aged children who have either dropped out of school or have never attended formal school, geographically isolated children, street and working children. The concept survival rate entails knowing the number of pupils who will complete the primary level of education up to the $5^{\text {th }}$ grade. This rate is calculated using the constructed cohort system and forecasts the likelihood that a pupil will survive to a grade assuming the current pattern of dropout and repetition rate (Cameron \& Laurie, 2005). This rate is necessary in the education sector as it helps policy makers in the education sector know at what level they are facing challenges in terms of primary education. However, there are factors that account for low survival rate in public primary schools' pupils and these range from those factors that originate from the school teaching program, the school environment itself 
as well as the society in which those pupils live. Hence this delicate level needs more attention from both the government and other stake holders as it impacts more on the future development of a country. However, there are many challenges encountered in this stage which in worst scenario leaves the education of the child compromised or halted. In their study, UNICEF estimated that $68.8 \%$ of pre-primary age children were out of school in 2014 , which leaves much to be desired as it hinges also on the moral fiber of the Zambian society. It is, therefore, important that the factors which contribute to such be identified and approached with the tools necessary for the development of holistic education system. Zambia has been affected by such factors which has led to low survival rates of primary school pupils and this impacts negatively on the education of the young population of the country, thereby leading to slow development of the nation.

It is noteworthy that the Government of the Republic of Zambia has put up sufficient policies, standards, instruments and domesticated international conventions aimed at guaranteeing quality education in the country but there seems to be some pertinent factors which pull out of schools these children between grade 1 and grade 5 .

\subsection{Problem Statement}

The education sector in Zambia generally faces challenges which in some cases result in not fully attaining the intended goals. Amongst these at primary school level is the low retention rate, which measures the rate of whether a newly entrant pupil will complete lower primary level i.e. grades 1 to 4 . Pupil retention in public primary schools remains the biggest challenge because it is not certain whether pupils entering grade 1 will eventually complete lower primary level (grade 5). This negative progression rate has an impact on resources that are invested in this sector. For instance, it was estimated that 84,880 pupils, or $16.7 \%$ of the total of 508,264 Grade 1 entrants in 2009 will drop out before completing Grade 5 and the investment for them will be wasted, (MOE, 2009). In terms of gender, the female retention rate to Grade 5 was lower than that of male even though more girls entered Grade 1. The number of pupils to whom investment will be wasted is nearly 10,000 more for girls than boys (boys 35,476, girls 45,150) (MOE, 2009). In Lusaka province, the figures were higher in repetition rate, dropout rate and retention rate, whereas transition rate was significantly lower than the average. There are many factors which lead to such for instance attendance rate of orphans has been lower than the children with parents by $10-15 \%$ (World Bank, 2006). According to the research in Central province, many orphans did not go to school every day and could not concentrate on classes even if they attend because of hunger, all of which resulted in low retention rate and high dropout rate (IOB, 2008). This process of pupils' low retention rate is ongoing as most of those who do not attend school are children who have enrolled but who have crossed the threshold from regular attendance to regular absence. The push or pull factors in both schools, communities and households are among factor which lead into low retention rate. This is an under-researched area even though the problem is prevalent. Knowledge around this can help illuminate some of the complexities around it and bring new insights to policy makers and educational practitioners as the number of children out of school has continued to swell from

This publication is licensed under Creative Commons Attribution CC BY.

http://dx.doi.org/10.29322/IJSRP.10.08.2020.p104111
195,000 (Education Statistical Bulletin) in 2015 to over 800,000 in 2019 (Lusaka Times, $3^{\text {rd }}$ May, 2019).

\subsection{Study Objectives}

\subsubsection{Main Objective}

To analyse factors accounting for low retention rates among public primary school pupils in Lusaka, Zambia.

\subsubsection{Specific Objectives}

(i) To describe pedagogical processes which lead to low retention rate among public primary school pupils in Lusaka District.

(ii) To explore school environmental factors which contribute to low retention rate among public primary school pupils in Lusaka District.

(iii) To analyse socio-economic factors responsible for low retention rates among public primary school pupils in Lusaka District.

\section{THEORETICAL REVIEW OF LITERATURE}

\subsection{Zambia's Demographic Overview}

The population of Zambia as at close of 2018 stood at 17.1 million people compared to about 3.45 million people at independence in 1964. Partly because of the country's high fertility rate, the population is growing at a rapid 3.3 percent per year resulting in the population doubling close to every 25 years (Masaiti et al., 2018; World Bank, 2018; CSO, 2017). Zambia is experiencing a large demographic shift and is one of the world's youngest countries by median age. The World Bank (2018) projects that this trend is expected to continue as the large youth population enters reproductive age, which will put even more pressure on the demand for jobs, education, healthcare and other social services. In terms of age structure, the population under the age of 15 years and below accounts for about 50 per cent while those under the age of 35 years' account for 70 per cent of the Zambian population (Masaiti et al., 2018). In terms of figures, $8,158,011$ are young people under the age of 15 years $(4,094,205$ males / 4,063,632 females), 8,876,572 are persons between 15 and 64 years old (4,461,085 males / 4,415,487 females), 435,888 are people above 64 years (186,934 males / 248,954 females) (World Bank, 2018) (CSO, 2017). In other words, the country overall has a young population which makes the provision of educational services to this population to be of strategic importance to government (EFA, 2015).

\subsection{Zambia's Education Policy Frameworks}

A policy is a statement of intent or guide to courses of action meant to realize intended benefits. In other words, it is a strategic use of resources in dealing with human challenges. The Zambian education sector has progressively devised and implemented various policy interventions in a bid to enhance service provision and delivery to the satisfaction of clients. Policies are also crucially important in helping monitor and evaluate intended goals and objectives. Masaiti et al., (2018) highlight five as the major policy documents from 1977 to date.

The first one being the Education Reform, Proposals and Recommendations document of 1977. The major undertaking of 
this policy was to try and address the distortions and deficiencies of the colonial education system which trained Africans to serve as labourers but failed to meet the needs of Zambians in the context of the new social, economic and political dispensation. It aimed to create an education system which met the needs and aspirations of Zambians and functioned as a powerful instrument for development of an independent nation (MoE, 1977). The Ministry noted that 'Education is a social institution which will continue to reflect the characteristics of the Zambian society' (ibid). From the spirit of the document, the ministry was aware that the achievement of universal basic education would require significant resources i.e. time, infrastructure, financial, material etc. The policy also opined the need for additional classroom space, teacher recruitment and consistent annual recurrent funding as basis for meeting the demand for quality education.

The second document was Focus on Learning, which concentrated on the development of primary education. It stated that, "the basic national policy in the education sector is to provide every eligible child with good quality education in Grades 1-7. The policy aimed to improve access, equity and efficiency and provide quality education through the rehabilitation of existing schools, building new ones, training education managers and procuring and supplying educational materials to schools. The policy emphasized the need for broad-based resource mobilization strategies to ensure its effective implementation (MoE, 1992) (Masaiti et al., 2018).

The third and current education policy is the Educating Our Future document of 1996 with its primary focus on quality, efficiency, equity, revitalized partnerships, decentralization and democratization. It aimed at ensuring that by 2015 every child should have had access to nine years of basic education (MoE, 1996) and prioritised literacy and numeracy in schools as critical to meeting the policy's blue prints. However, Masaiti et al., (2018) regrettably state that this policy's effective implementation has met serious glitches as learner achievements are still very low. In a bid to ensure accessibility, affordability, equity, relevance and quality of education service provision to all eligible persons, the government of the Republic of Zambia enacted a Universal Free Primary Education Policy was envisioned to exponentially increase equity, affordability, quality, relevance and accessibility to education by all and promote socioeconomic well-being of all citizens, and to achieve a good quality of life for everyone (Phiri, 2015; GRZ, 2002; and Ministry of Education, 2003).

In 2006, Zambia enacted a Vision 2030 which envisions the country to be, "a prosperous Middle-income Nation by 2030." This document was declared as reflecting the collective understanding, aspirations and determination of the Zambian people to be a prosperous middle-income nation and has been the accepted by successive governments to date as a standard of the country's progress, focus, actions etc. This document equally recognizes the central role of education in achieving its blue print objectives and gave strategic focus on what needed to be done in the education sector in the exodus to the 2030 promised land. It envisions among others, reduced pupil/book ratios, increased enrollment rates, reduced gender parity index etc.
The foregoing indicated policy documents highlight the country's long and progressively engrained desire to provide localized and quality education as a formidable foundation to the country's socio economic development. As a matter of fact, the vision of the Ministry of General Education (MoGE) is to provide, "Quality, Lifelong Education for all which is Accessible, Inclusive and Relevant to an Individual, National and Global Value Systems" (MoGE, 2019). With the current policies tilting more towards accessibility, equity, efficiency and relevance, there is an equal emphasis on the need for sustainable financing, among others, in order to meet these education benchmarks. What is so clear in the current policy is that the learner achievements during the subsistence of this policy are very low, which claim constitute a fundamental indictment and requires investigation for root cause. While the policies, among others, purposed to ensure provision of basic education by 2015 , the picture on the ground seems to suggest that the number of children out of school is on a steady increase from 2015 (which is the direct opposite) (ESB,2015, and Lusaka Times, $3^{\text {rd }}$ May, 2019).

\subsection{Exploring Low Retention Rate Factors}

Admittedly, there are mosaic factors which could be responsible for low retention rate among public primary school pupils but this study focuses on three broad categories, namely: pedagogical, environmental and social factors.

\subsubsection{Pedagogical Process Factors}

Research by Scheerens (2000) and Verspoor (2003) suggest that in developing countries the influence of the school on pupil learning is more important than the effect of home and other external factors compared with developed countries. Changing pedagogic practices suggest the need for powerful school-based specialized development programmes as many teachers are unprepared or underprepared to teach and thus developmentally handicapped at the pre-service phase. Intervening at the school level and classroom level is seen as being crucial in raising the quality of primary education in Africa as ultimately educational quality is obtained through pedagogical processes in the classroom. This is achieved through the knowledge, skills, dispositions and commitments of the teachers in whose care pupils are entrusted (Craig, Kraft, \& Plessels, 1998; Anderson, 2002; Verspoor, 2003). Therefore, managing the quality of classroom interaction is seen as the single most important factor in improving the quality of teaching and learning, particularly in contexts where learning resources and teacher training are limited.

For example, evidence from Botswana (Arthur et al, 1996), Kenya (Pontefract \& Hardman, 2005), Tanzania (Osaki and Agu, 2002); South Africa (Chick, 1996) and Nigeria (Onocha and Okpala, 1990), shows that teacher- pupil interaction often takes the form of lengthy recitations made up of teacher explanation and questions, mostly teacher driven pedagogy, which places pupils in a passive role and limits their learning to memorising facts and reciting them back to a teacher, and this appears to have had little impact on classroom practice (Anderson, 2002; O'Sullivan, 2004). This can be demotivating to pupils as the routine do not promote creativity and can add to low survival rate. Birdsall, Levine \& Ibrahim (2005) question the quality of schooling systems in lowperforming countries, where the institutional and management challenges are 'significant'. They describe institutions with high 
teacher absenteeism; spending and investment which is unresponsive to local needs and preferences; a lack of accountability and incentives for performance. Hunt (2007) also describe the lack of accountability and monitoring mechanisms in some schools. Ghuman and Lloyd (2007) note how teachers once hired are difficult to fire, meaning performance and attendance are difficult to guarantee; and Hunt (2007) centers on a lack of monitoring of policy in practice. Such vices and poor service delivery at schools, such as teachers not being able to finish the syllabus, poor work culture where less attention is paid to academic development of pupils and low pupil teacher ratio where only a few pupils receive attention for their school work result in less morale of pupils towards academics. This can be a critical contributor to low survival rate as this hinders the pupils learning phase.

In terms of human resources, research indicates that female teachers often have an important impact on schooling quality for female pupils (Colclough \& Lewin, 2000). However, the availability of female teachers in some countries is low, and particularly in the higher grades of schooling. For example, in Colclough \& Lewin, (2000) research, some of the rural schools visited in Guinea and Ethiopia had no female teachers; this is not uncommon. Schools without, or with few, female teachers are often less attractive to parents/guardians on the grounds of security of female students and provides fewer role models to motivate female pupils towards continued attendance.

School facilities, availability of resources, such as textbooks, desks, blackboards have been noted to influence survival rate (Brock \& Cammish, 2000). The availability of (separate) sanitary facilities is important for female preservation, particularly as girls get older and start menstruation (Lafraniere, 2005). In research by Colclough, only 5 of the 11 schools visited in Ethiopia had latrines, and, of these, only one was separated for boys and girls. This affect the education attainment for the pupils and has been attributed to contribute to low survival rate observed in the primary level of education. As these are basic requirement in the school setup.

\subsubsection{School-Environment Factors}

Despite embracing free primary education as early as 2002, most of the countries have not achieved a hundred percent primary school child survival rate to the last grade. An example of the effect of policy changes on the completion rate is provided by Zambia's recent experience. In February 2002, the Ministry of Education announced free primary education which was reenforced in 2019. In addition, it began the process of expanding access to education in grades 8 and above. However, there were still factors that negatively affected the learning of the pupils in public primary school which can be attributed to the school environment. A study by Manzo (2006) revealed that the introduction of free primary education in some Sub-Sahara African countries led to an increase in enrolment such that classrooms in government primary schools were filled beyond normal capacity. Additionally, (Duncan et al, 2003) contend that, due to this rise in enrolment, the grants could not purchase critical resources needed for effective teaching and learning. Moreover, the grants were often and are still not released on time and are inadequate. As was further noted in another study, for many schools, the grants were still not sufficient enough to meet the overwhelming needs and several schools reacted by raising PTA fees at the upper basic school level (Grades 8 and 9). Moreover, IOB (2008) asserts that, "the pupil teacher ratio increased from 49:1 between 2002 and 2003 to 57:1 in 2005" In some cases, there was congestion in classrooms with an average number of 77 pupils per class. The pupil book ratio rose to $18: 1$ and six pupils could share a desk and in extreme cases eleven children could use one desk (Chengo et al., 2005). Additionally, grants could not meet costs for utility services like water, electricity and security. To make matters worse, many schools were not decided on what type of fundraising ventures to embark on to raise additional funds. The pupil performance in numeracy and literacy was and is still poor with only $33 \%$ pass rate due to overcrowding. Such an education environment is attributed to low survival rate as some pupils will abscond classes due to their reasoning that they will not find enough desk to seat on at school and the hash classroom environment would bleed conflict as each pupil would seek attention which the teacher is sufficiently unable to provide.

Clean environment leads to a sound mind, with budgetary constraints and inadequate infrastructures such as toilets and clean water in universal primary schools; one wonders whether with limited budget, schools can have adequate facilities to make conducive learning environment for the pupils (Galimak, 2008). In similar studies in Uganda, in 2000 , only $8 \%$ of all universal primary schools had sufficient latrines for the pupils, and only one third of these schools had separate latrines for girls. This implies that $92 \%$ of all schools suffered from lack of latrines and two thirds had no separate toilets for boys and girls. This has a negative effect on the children's survival in schools as many of them drop out of schools due to sanitation related sickness (Galimak, 2008). A study by World Bank (2006) stipulates that some of the contributing factors to the poor performance and absenteeism at primary level were: delayed disbursement of funds, inadequate teaching and learning materials and desks, reduced pupil teacher contact time, inadequate funding for bursary support to meet ever increasing demand due to increase in the number of orphans and vulnerable children and continued existence of classroom congestion due to limited infrastructure and this has continued to compromise the quality of education, leading to poor quality being seen as a major challenge. According to Orlosky (1984), adequacy of finance and its effective management determines the way the school is managed and whether or not the school will meet its objectives. If finances from the government are not adequate, then the schools are not able to procure all the necessary goods and services needed to meet their objectives (Mobela, 2016) for a conducive learning environment.

The government through education policies has been trying to address the challenge by providing school facilities, improving school infrastructures, supplying test and reference books and allocation of teacher. Despite this effort of the government actually what teachers do in their schools and classrooms depends on how teachers perceive and respond to their working environment. In a research conducted by Galimak (2008), it was noted that education's curriculum content and teaching method should be relevant and responsive to different circumstances and needs of children. Teaching techniques, learning methods and materials need to be child centered and appropriate for children. In addition, teacher's capacity, morale, commitment, status, income and recognition to child right should be ensured (Theis, 
2004). With regard to most schools, this has been more of a myth than a reality because schools are associated with threats such as, hunger, corporal punishments, violence and insecurity of which they are more pronounced in war areas, as a result, there is low survival rate as children dropout of school since their security is not guaranteed (Tomasevski, 1999).

\subsubsection{Socio-economic Factors}

Social factors which have contributed to this include household income as schooling potentially incurs a range of costs, both upfront and hidden. Household income is linked to a range of factors: when children start school, how often they attend, whether they must temporarily withdraw and when and if they will stop schooling (Croft, 2002). Porteus et al., (2000), whilst describing exclusions rather than whether the child will survive as per se, paint poverty as 'the most common primary and contributory reason for students to be out of school' and Hunter and May (2003) call poverty, 'a plausible explanation of school disruption'. For example, Brown and Park's research in rural China (2002) saw 'poor and credit constrained children' three times more likely than other children not to complete primary school. If income levels are low, children may be called on to supplement the household's income, either through wage-earning employment themselves or taking on additional tasks to free up other household members for work. This is more apparent as children get older and the opportunity cost of their time increases. In Boyle et al, (2002) research in some areas of Uganda and Zambia, the inability to pay school fees meant children withdrawing from school for periods of time, however temporarily. Also the fact that universal primary education removed only school fees and PTA charges and left intact other costs such as: exercise books, pens, pencils, uniforms, clothing, lunch, building funds and labour for classroom construction to be met by the parents (MFPED, 2002), it may explain the low levels of accessibility and survival rate in primary schools.

However, what is not assured is whether most children will be able to able to attend school uninterrupted - not merely because of ill health but also because they may need to work, and the existing school does not motivate them or their parents to attend/send them to school. Attendance is erratic and chronic absenteeism often the norm - especially for older boys and girls. In other instances, both boys and girls also work before and after school, engaging in a wide range of chores - domestic work, sibling care, and filling water (Vimala, 2008).

Community participation is one of the more misused and misunderstood words in the development literature. Therefore, at the outset, it is important to define community participation in the specific context of primary education - referring to those parents whose children are enrolled in government schools or those who are participating from the margins (Vimala, 2008). In the specific context of government school's community participation should ideally involve people who have little or no access to basic education but have a greater stake in the school. However, these are the very people who are the most difficult to reach out to. The poorest are caught up in the daily battle for survival. From their perspective, education that does not lead to any tangible or intangible gain can be dismissed as being irrelevant. If children are found in a community that views education with such lenses, there survival at primary level is compromised as they lack motivation or pushing parents or community member to ensure they stay in school.

Child labor create pressure on a child's time, for example, children who combine work with school, depending on the nature and volume of work, can have erratic school attendance, regular school absences (Croft, 2002) or increased instances of lateness. Children living in slum areas or without permanent residence may move frequently, often leaving school as a result (Chitnis \& Suvan, 2004). A full-time work schedule paired with primary education for a ten-year old pupil cannot be sustainable, nor can it be adequate preparation for successful passage of examinations and transition to secondary school. The burden of labour placed on pupils must be defrayed to enable pupils to pursue an unhindered course of primary education.

The community is aware of the need for educating their children yet the children are burdened with work before and after school, during holidays and vacations - both household/domestic and sibling care related chores as well as work outside the home or in homebased occupations. This obviously directly impacts on the learning abilities of children - especially when they put in long hours every day. Most children in poor households do not get time to revise / read their books - especially girls who are higher up in the birth order. Given the nutritional status of poorest children, energy levels are low and impact upon children's ability to concentrate in school. The impact of working and yet attending school needs to be examined with reference to its impact on learning outcomes.

Whilst being orphaned is often linked to an increased likelihood of childhood poverty, this is dependent on the household context and who then becomes the child's care. Orphan hood often exacerbates financial constraints for poorer households and increases the demands for child labor, (Bennell et al., 2005) and less opportunity to continue with education demands.

Research also indicates that school-aged children who suffer from protein-energy malnutrition, hunger, or who lack certain micronutrients in their diet do not have the same potential for learning as healthy and well-nourished children (Pridmore, 2007). Studies suggest that these children attend school less frequently, are more likely to repeat grades, drop out early and fail to learn adequately due to poor levels of attention, low motivation and poor cognitive function (ibid). Hence the problem of low survival rate needs to be addressed so that the policy makers can find ways of combating the issue for both proper use of invested resources in education and for social development.

\subsection{Theoretical Underpinnings}

Low retention rate is viewed generally as the possibility of a newly entrant pupil in grade one to survive primary school-age especially up to grade 5 . The factors which lead to the survival are associated with the school life that a pupil goes through especially that he or she is at a dependant level and the decisions are being made on their life. If the people responsible for the child's education are unable to identify factors that affect the pupil's academic up bring, there can be a misunderstanding as to why the child switches from being interested in education or the poor performance as a result. Theoretically, the child's cognitive development is at its tender stage and the decisions that he or she makes will depend heavily on the current situations being encountered. The study is anchored upon the human capital theory, which stresses according to a study conducted by Mobela 
Carlos, on impact of free primary education, and holds that the well-being of a society is a function not only of the traditional stocks of financial capital, labour and natural resources but also of the knowledge and skills of individuals (Mobela, 2016). This theory predicts that increased knowledge and skill will yield improved economic outcomes for both individuals and societies, especially in modern societies, where it is widely held that knowledge and skill convey a greater economic and social premium than in the past. It is from this theory that if low survival rate in primary school pupils is prevalent, this will impact the education sector negatively and the resources invested will not yield the expected outcome just as is in a company, the capital invested in the production is expected to yield returns. This theory was also used by authors such as Adams Smith (1776) and Alfred Marshall (1890), who concluded that 'a man educated at the expense of much labour and time may be compared to one of those expensive machines and the work he learns to perform should repay him the whole expense of his education, and also the time and money spent on education builds human capital hence one should be able to estimate the rate of return on such investment, in a way similar to investment in physical capital (Mincer et al 1958). By tackling these factors, the pupils at a primary level will be able to crossover to secondary level and their invested resources benefiting both the child and the nation at large. Economic analysis has consistently shown that investment in education brings higher rate of return than investment in physical capital (Woube, 2003). Changes in the education arrangement of any country must give due attention to the efficiency and effectiveness of primary education. "The progression of pupils from admission" in the beginning year of their study "until their successful completion" of the cycle of education (primary or secondary) reflects the degree of efficiency in that level of education (UNESCO, 1983). It is therefore important to note that education is the driving force behind any strong economy and a prerequisite

Independent Variables Dependent Variable

\begin{tabular}{|l|l|}
\hline Pedagogical Factors \\
\hline \hline Environmental Factors \\
\hline Socio economic Factors \\
\hline
\end{tabular}

Figure 1: Conceptual Framework

Source: Author's Construction (2020)

\section{METHODOLOGY}

A survey method was employed incorporating a qualitative research paradigm. The qualitative study design was used as it is more holistic and often involves a rich collection of data from various sources to gain a deeper understanding of individual participants, including their opinions, perspectives, and attitudes. Qualitative research gathers data qualitatively, and the means of analysis is also primarily qualitative. This often involves an inductive examination of the data to find recurring themes, for social and economic growth. It creates opportunities and provides societies with a better educated and skilled workforce which is necessary for stimulating development (Govender and Steven, 2004). Hence there should be high completion level at primary level so that every citizen gains a chance to basic literacy such as writing, reading and arithmetic's for a better society

\subsection{Conceptual Framework}

Accordingly, conceptual framework is a set of broad ideas and principles taken from the relevant field of enquiry and used to structure a subsequent presentation (Kombo and Tromp 2006). In the ideal situation, all students admitted in the beginning grade of the education level will reach the second grades in the following academic year and continue until they complete that level of education. But in reality "an alarming phenomenon in education", wastage (drop-out and repetition) obstructs this "ideal scheme" (UNESCO, 1983). If all the pupils enrolled at entrant would complete primary level, it would bring about productivity and economic wellbeing of the citizens. However, this ideal situation is unattainable especially in most developing countries, Zambia inclusive, because of the resource constraint that most face. This study conceptualises the prevalent factors as being lack of finances to build enough educational infrastructure that are basic needs, lack of proper curriculum developments that ensures efficiency and effective learning structure and social economic factors that young learners go through. In a nutshell, this study centres mainly on the low survival rate and the factors that lead to this which are basically classified as pedagogical processes, school environmental factors as well as social factors. These factors when studied will be able to demonstrate that the pupils' inability to complete primary level can be attributed to such factors and that there is also a relationship among these factors (variables) and the low survival rate of public primary school pupils patterns, or ideas (Shank, 2006) and then describing and interpreting those categories. The study targeted 66 public primary schools in Lusaka district as at 2020 out of which 10 were randomly selected. The questionnaires were distributed to 10 selected public primary schools in Lusaka. The study sampled a total of 100 respondents who were to be given self-administered questionnaires with the researcher carrying out the activity on-thespot-basis. The respondents comprised head teachers, deputies, senior teachers, school counsellors, teachers and school administrators. Questionnaire responses were subjected to 
analysis using excel and SPSS to gain in-depth understanding of the phenomena with the results being presented in charts, figures, tables and graphs while minor content responses were presented in text format. The researcher equally maintained mandatory ethical norms by implementing informed consent, anonymity, confidentiality, and citation of all materials with references being listed at the end of the study.

\section{ANALYSIS OF FINDINGS}

\subsection{Pedagogical Factors}

Teachers have a huge responsibility of both imparting knowledge as well as building the children entrusted to them. This is achieved through the knowledge, skills, dispositions and commitments of the teachers in whose care pupils are entrusted (Verspoor, 2003)

From the data collected and analysed, it shows that there are some teaching approaches which contribute to low retention rate among primary school pupils. Some teaching methods such as those which expose the pupils' illiterate levels can discourage some pupils to attend school hence the need for teachers to be sensitive, diligent and wise in dealing with pupils' vulnerability. The other factors which came out strongly as prohibitive to pupils' retention were teachers' qualifications, teacher's level of lesson preparedness, and teacher's attitude / commitment to his/her professional calling. On these factors, respondents scored generally above average in agreement of the resounding impact the factors have on pupils' endurance especially in lower levels. By implication, teachers were supposed to apply with wisdom the skills garnered from their training in sociology, psychology, philosophy, teaching methods / approaches, principles of teaching etc to create a conducive learning environment user-friendly to all learners. This is a more reason why the training of teachers need particular attention to ensure alignment to pupils' learning needs but more so the design/framing of the school curriculum. It is quite clear that the Zambian curriculum framework is not tailor-made to a large extent as all learners are required to take up even subjects which are way off from their references and experiences to their detriment. There is also still seemingly a mismatch between the curricular of education training institutions and learner curriculum, which also bring a dynamic set up in the whole learning process of the child at the level in question as both the pupil and the teacher are seemingly at trial and error with a victim ultimately being a learner.

Research by Scheerens (2000) and Verspoor (2003) suggests that in developing countries the influence of the school on pupil learning is more important than the effect of home and other external factors compared with developed countries. Changing pedagogic practices suggests the need for powerful school-based specialized development programmes as many teachers are unprepared or underprepared to teach and thus developmentally handicapped at the pre-service phase. In the QSQS Report (2015) by World Bank in Zambia, it came to light that a number of teachers were not qualified to teach their respective classes. About $22 \%$ of grade 5 school teachers have GCE or lower degree qualifications. More importantly, the process of recruiting teachers in public schools is less stringent since it does not involve any interviews unlike is the case with other public service employees. Thus, even less competent teachers ultimately end up being employed due to poor selection processes that are prone to corruption and nepotism (Hapompwe, Karim, Kambikambi \& Milimo, 2020a).

\subsection{Environmental Factors}

The school environment encompasses classroom arrangement, classroom population, school's outside arrangement and physical appearance, water and sanitation, furniture, facilities like computers, digital projector / television sets to excite / ease learning, text books, internet and any other necessary infrastructure. From the data collected, the respondents were able to relate the low retention rate to an unconducive school environment. Clean school environment leads to a sound mind but with budgetary constraints and inadequate infrastructure such as toilets and clean water in universal primary schools, one wonders how schools can have adequate facilities to create conducive learning environment for the pupils (Galimak, 2008). The results showed that $53.1 \%$ agreed that a school environment plays a significant role in learner retention rate while $8.2 \%$ strongly agreed to this. On the other hand, $21.4 \%$ of the respondents disagreed with $2.0 \%$ strongly disagreeing while the other $6.1 \%$ of the respondents were neutral about about the phenomena.

In buttressing the foregoing, it should be stated that school environment is of utmost importance in determining the continuity of a new entrant pupil. It has to do with various input factors which aid and motivate the learner to keep in school. According to Hapompwe, Karim, Kambikambi \& Milimo, (2020a), some notable factors responsible for the low learner performance have been identified as inadequate trained teachers especially in Science and Mathematics; inadequate teaching and learning materials for the new curriculum; low teacher motivation and absenteeism; high pupil teacher ratios; ineffective school management and supervision; poor administration of the transfer policy for teachers; and inadequate funding at school level.

Empirically, according to the 2015 Educational Statistical Bulletin, the pupil/book ratios for both English and Mathematics was at 4:1 in 2015. While the book ratios for Zambian Languages and Life Skills was 5:1 and 7:1 respectively. The figures show that there is little or in some cases, no difference at all in the pupil-totextbook ratios between urban and rural based primary schools. Latest statistics indicate that five primary school students share less than 1 textbook for each subject (1 for Mathematics, 0.9 for English, and 0.9 for Science) (World Bank, QSQS, 2015). Additionally, the 2015 figures from the Educational Statistical Bulletin further demonstrate that learners in Grades 1-4 spend 3.9 hours in the classroom, while learners in Grades 5-7 spend 5.3 hours per day which are way too low. Schooling hours per student are much more affected by the school's location - urban or rural. Worse still, this contact time is based on the scheduled learning hours on the official school calendar and therefore does not include time lost as a result of premature school closures, learner or teacher absenteeism, examination period closures or time allocated to sporting activities (ESB, 2015; World Bank, 2015).

\subsection{Socio Economic Factors}

Socio economic factors have been known to be among the major contributors to the pupils' low retention rate in most public primary schools. Among these factors include but not limited to; family economic background, whether a pupil is orphaned or not, family size, educational background of the parents/guardians and also the community values and norms. In the current study, 
respondents indicated that some pupils were unable to complete primary school level because the parents failed to meet the school requirements such as uniforms, user fees, buying school books and other needs. Household income is linked to a range of factors: when children start school, how often they attend, whether they must temporarily withdraw and when and if they will stop schooling (Croft, 2002). The data collected from various schools showed $32.7 \%$ agreed and $14.3 \%$ agreed and strongly agreed respectively that some children withdraw from school because their families were unable to meet the school requirements / needs while $32.7 \%$ disagreed with the $11.2 \%$ being neutral about this variable. Additionally, child labour became another prominent factor linked to poverty as causal to low retention rate. Children who are given so many responsibilities at home are likely not to perform better at school. Some of the responsibilities such as house chores, looking after the young siblings and the old people have been a contributor to low retention rate. The opportunity that the children have to go to school is channeled to help at home hence denying them the chance of attending classes. This eventually discourages the child from taking their education serious. From the obtained data, $60.2 \%$ of the respondents agreed that home responsibilities were among the causes of low retention rate of the pupils in public primary schools and $20.4 \%$ of the respondents strongly agreed. On the other hand, only $2.0 \%$ of the respondents disagreed and $11.2 \%$ of the respondents were neutral about this. Child labor creates pressure on a child's time. For example, children who combine work with school, depending on the nature and volume of work, can have erratic school attendance, regular school absences (Croft et al., 2002)

Other social factors such as poor nutrition that the child faces contribute to low retention rate. The pupils who do not obtain a proper diet or lack food at home find it hard to go to school which leads to missing classes regularly, and if they go, they are unable to concentrate. The data obtained from the various public primary schools showed that the majority, that is $25 \%$ strongly agreed and $21 \%$ agreed that a poor nutrition is also a contributor to low retention rate. However, $26 \%$ of the respondents disagreed that food has a role to play in pupils' low survival rate.

Corroborating with the study's findings, according to UNICEF, out of the 500,000 children who were out of school in 2014 , the majority were from poor families. Rural children are again much more likely to be out-of-school with almost a quarter ( 23 per cent) of primary age children not in school compared to only 9 per cent in urban areas. Differences are even more marked among socioeconomic groups with out of school rates of 26.9 per cent among primary school age children from the poorest families compared to only 4.3 per cent among children from the richest families. Children in Eastern, Luapula, and Western provinces are particularly disadvantaged, especially the girls in Luapula and the boys in Western with out-of-school levels of 28.7 per cent and 31.4 per cent respectively. The national average for the entire age group is 18.3 per cent but this masks the fact that nearly a half of all 7 year olds and a quarter of all 8 year olds are out-of-school, suggesting a large and widespread problem with late entry (UNICEF, 2014).

It should be stated that the poverty levels in Zambia are so high that they affect children's ability to continue with school owing to hunger, malnutrition, lack of school fees i.e. user fees etc. In 2010, the moderate poverty rate in rural areas was 74 percent, more than double the urban poverty rate of 35 percent. Because roughly twothirds of the population lives in rural areas, the countryside is home to 80 percent of Zambia's poor. Rural poverty is also far more severe: almost 90 percent of Zambians living below the extreme poverty line are concentrated in rural areas. This is largely an effect of uneven income growth in the urban and rural economies. Rising incomes have been densely concentrated among a relatively small segment of the urban workforce, while high urban unemployment rates effectively block the rural labor force from participating in the country's more dynamic economic sectors (World Bank, 2012). In absolute terms, 5.1 million Zambians were living in extreme poverty, with 7.9 million in moderate poverty in 2010, indicating still a significant size of population under poverty. Among other factors prohibiting effective progression of children with school include child labor, state of being parented, segregation of roles between boys and girls etc. (UNICEF, 2014). The lop-sided aspect of it all is the fact that even siblings of these children who could be of help in their education are trapped in unemployment cycle. According to the World Bank Report (2015) in Zambia, the youth, aged between 15 and 24 , account for more than 40 percent of the total population, representing a youth bulge, which may be translated into a demographic dividend if complemented by economic and social opportunities for the youth. While the youth constitute 30 percent of the total labor force, their unemployment rate is more than 15 percent, which is almost twice as high as the average unemployment rate of 7.9 percent. This means that of the unemployed population of 459,132, almost 60 percent are the youth aged between 15 and 24 (Zambia Central Statistical Office, 2013). One of the reasons for the high level of youth unemployment is that the youth tend to lack the skills, competences and attributes required by the labor market (Koyi, Masumbu, \& Halwampa, 2012).

Notwithstanding the foregoing vicious poverty circle description of the Zambian scenario, it should be chronicled that the Government of the Republic of Zambia through the Ministry of General Education with co-operating partners has had measures to ameliorate or demystify the impact of poverty on learners' academic progression especially at primary school level. Among the prominent measures were the declaration of free primary education meant to remove the barrier of accessibility and affordability. Besides, government initiated feeding programmes and social welfare sponsorship packages for orphans and vulnerable children across the country. However, empirical evidence in Hapompwe \& Kambikambi (2020b) study in Lusaka indicates that government's education financing to the education sector has been on a steady downward declension from 2015's $20.2 \%$ to 2019 's $12.2 \%$ of national budget against UNESCO's $20 \%$ threshold, ostensibly implying inadequacy in resources to meet the above education necessities for smooth operationalization of the sector and subsector in particular. The study further unearthed government's inadequacies and inconsistencies in grant disbursement to schools thereby leaving no financial resources to sustain the operation of public primary schools which solely depend on government financing for all termly expenditure. In the other study by Hapompwe, Karim \& Kambikambi (2020c) which analyzed threats to the sustainability of Free Primary Education, it was established that withdrawal of donors' education financing, population upswing against static 
education expansion, economic recession and financial mismanagement were frantic factors to poor quality education currently prevalent in the sector and subsector alike.

\section{CONCLUSION}

The equitable supply of trained teachers along with physical input factors in public primary schools is of paramount importance to maintaining a higher retention rate among pupils. This should be augmented by an enhanced and improved parents' economy through government's deliberate efforts to ensure a conducive and supportive socio economic environment for children's quality education sustainability. Without a cautious policy intervention which should include revitalised education financing to the threshold, inclusive education quality will remain a pipeline dream

\section{REFERENCES}

[1] Anderson, A., Hamilton, R. \& Hattie, J. (2004). Classroom Climate and Motivated Behavior in Secondary Schools. Learning Environments Research, 7: 211-225.

[2] Andrews, J. (2011). Educational Dialogues: Understanding and promoting productive interaction. International Journal of Lifelong Education, 30(6): 831-832.

[3] Arter, J. \& Stiggins, R. (2005). Formative assessment as assessment FOR learning. National Council on Measurement in Education Newsletter, 13(3): 4-5.

[4] Barber, M. (1996). The Learning Game: Arguments for an Education Revolution. London: Gollancz Cassell Group.

[5] Barber, M. (2007). Instruction to Deliver: Tony Blair, Public Services and the Challenge of Achieving Targets. London: Politico's.

[6] Cameron, Laurie (2005). Primary Completion Rates. Technical Paper WP09-01. Education Policy and Data Centre, Washington, D.C :(FHI 360).

[7] Central Statistical office. (2017). Census of Housing and Infrastructure. Lusaka: CSO.

[8] Colclogh, C. and Lewin, K.M. (1993), Educating All the Children: Strategies for Primary Schooling in the South, Oxford: Clarendon Press.

[9] Davison, J. (1993). School Attainment and Gender: Attitudes of Kenya and Malawian Parents towards Educating Girls; International Journal of Educational Development,

[10] Graham Brown, S. (1991). Education in developing world: Conflict and Crisis. London Longman INC.

[11] Educating Our Future (1996) Revised in 2016. National Policy on Education. Lusaka: MoGE

[12] Education Sector Bulletin (ESB) (2017). Ministry of General Education (MoGE), Lusaka.

[13] Education Sector Bulletin (ESB) (2016). Ministry of General Education (MoGE), Lusaka.

[14] Education Sector Bulletin (ESB) (2015). Ministry of General Education (MoGE), Lusaka.

[15] Hapompwe, C. C., Karim, A. M., Kambikambi, T. T. \& Milimo, V. (2020a). Assessment of Factors Accounting for Low Learner Outcomes in Core Subjects Among 5th and 9th Graders in Zambia's Public Schools. African Journal of Education and Practice, 6 (1), 1 - 18.

[16] Hapompwe, C.C. and Kambikambi, T.T. (2020b). Sustainability of Universal Free Primary Education Amidst Declining Education Financing. African Journal of Education and Practice. ISSN 2519-0296 (online) Vol.6, Issue 2. No.5. pp $62-78$.

[17] Hapompwe, C. C., Karim, A. M. \& Kambikambi, T. T. (2020c). An Empirical Evaluation of Public Secondary Schools' Education Financing and Its Impact on Service Quality in Lusaka, Zambia. African Journal of Education and Practice, 6 (2), 13 - 32.

[18] Kotwal, N. \& Rani, S. (2007). Causes of School Dropouts among Rural Girls in Kathua District. Journal of Human Ecology, 22(1): 57-59. [Online]
Available: http://w.krepublishers.com/...2007...2007...Kotwal-N/JHE-2 2-1057-07...

[19] Lusaka Times Newspaper; Education Sector Has Not Received any Funding for 2018 as at 17th July, 2018. Lusaka: Zambia.

[20] Lusaka Times Newspaper; Number of Children out of School Rise to 800,000; 3rd May, 2019. Lusaka: Zambia.

[21] Mandina, S. (2013). School Based Factors and the Dropout Phenomenon: A Study of Zhomba Cluster Secondary Schools in Gokwe District of Zimbabwe. Journal of Educational and Social Research Vol. 3 (1), 51-60.

[22] Mbita EMIS (2012). Annual Educational Assessment and Evaluation Reports. Unpublished.

[23] Maton, K. \& Moore, R. (2010). Social Realism, Knowledge and the Sociology of Education: Coalitions of the Mind. London: Routledge.

[24] Matthews, B. and Ross, L. (2010). Research Methods: A practical Guide for the Social Sciences. Edinburgh Gate: Pearson Education Ltd.

[25] Maxcy, S. J. (2003). Pragmatic threads in mixed methods research in the social sciences: The search for multiple modes of inquiry and the end of the philosophy of formalism. Handbook of mixed methods in social and behavioural research, 51-89.

[26] Maxwell, L. E. (2007). Competency in childcare settings: The role of the physical environment. Environment and Behaviour, 39(2), 229-245

[27] Masaiti, G. (ed.) (2018). Education in Zambia at Fifty Years of Independence and Beyond. Lusaka: UNZA Press.

[28] Ministry of Education (2003). Strategic Plan 2003-2007. Lusaka: Ministry of Education HQ.

[29] Ministry of Education. (1992). Focus on Learning. Lusaka: Government Printers.

[30] Ministry of Education. (1977). Educational Reforms: Proposals and Recommendations. Lusaka: Government Printers.

[31] Mobela, C. (2016). Impact of Free Primary Education: A Case Study of Government Schools in Kabwe Urban District. International Journal of Multidisciplinary Research and Development, Vol. 3(9), 48-60.

[32] MoGE. (1996). Educating Our Future: National Policy on Education. Lusaka Zambia Publishing House.

[33] MoGE. (2019). Ministerial Statement to Parliament - School Fees Reduction in all Public Schools in Zambia. Lusaka: MoGE.

[34] Oghuvbu, E.P. (2008). The Perceived Home and School Factors Responsible for Dropout in Primary Schools and Its Impact on National Development. Ekpoma Journal of Behavioural Sciences, 1, 234-235.

[35] Phiri, G.G. (2015). The Impact of Free Primary Education in Zambia: A Case of Chipata District - Eastern Province. Masters Dissertation. University of Zambia.

[36] Pontefract, C, \& Hardman, F. (2005). The discourse of classroom interaction in Kenyan primary schools. Comparative Education 42 (1), 87-106.

[37] Schultz, T. W. (ed.) (1961). Investment in Human Beings. Journal of Political Economy, 70 (5, part 2).

[38] The Mast Newspaper (Online) - Lusaka. Unqualified Teachers Damaging the Learners; 5th September 2017.

[39] UNESCO - Zambia (2018). Annual Report - 11th Ed. Lusaka: UNESCO.

[40] UNICEF (2014). Global Initiative on Out-of-School Children Report. Lusaka: UNICEF Office.

[41] World Bank Group. (2018). The World Bank Group in Zambia - Report No 128467-ZA. Lusaka: World Bank.

[42] World Bank Group. (2017). The World Bank Group in Zambia. Lusaka: World Bank.

[43] World Bank. (2006). Strengthening Evidence-based Policymaking with Education statistics and Analysis Report; Re535635. Ukraine.

[44] World Bank Group. (2015). Education Global Practice: Zambia Education Public Expenditure Review at a Glance. International Bank for Reconstruction and Development: Washington DC

[45] World Bank. (2012). Zambia Poverty Assessment: stagnant poverty and inequality in a natural resource-based economy. Washington, DC: World Bank.

[46] Zambia's Vision 2030 : Education for All 2015 National Review Report: Zambia.(efa2015reviews@unesco.org) 


\section{AUTHORS}

First Author - chapompwe@ cavendish.co.zm /

chrinehapompwe@yahoo.com 